\section{Todo lo que he aprendido con la psicología económica*}

Sergio Alfonso Durán Pérez ${ }^{\S}$

El libro aquí referido resulta una adquisición obligatoria para todo aquel que quiera saber el origen, el desarrollo y las implicaciones de la economía conductual. Su estructura permite usarlo como libro guía en un seminario avanzado de economía, dada la riqueza y rigurosidad de sus referencias bibliográficas; o como libro introductorio para un lector desprevenido sin bases sólidas en teoría económica clásica, al no sacrificar la fluidez y el lenguaje amigable que genera un interés genuino hasta la última página.

Sobra decir que Richard Thaler fue merecedor del premio Nobel de Economía en $2017^{1}$, y al abordar este libro resulta evidente por qué: una vida académica destacable, en donde las pocas cosas con las que el lector puede discrepar con el autor es autodenominarse perezoso, pues su obra da muestra de todo lo contrario; por lo menos en lo que respecta a sus contribuciones a las Ciencias Económicas. $\mathrm{Si}$ bien la estructura del texto toma como punto de partida varios acontecimientos de su vida profesional, no por eso se torna una lectura anecdótica y superficial; al contrario, la manera en la que enlaza estas etapas vividas con la institucionalidad y los avances de la economía conductual, resulta coherente y llamativa.

La estructura general consta de ocho partes, se recomienda abordarlas en el orden correspondiente. Los dos primeros capítulos (Factores supuestamente irrelevantes, FSI, y El efecto dotación), se toman como punto de referencia en la mayoría de los capítulos posteriores. Los FSI dan cuenta de esa insatisfacción que caracteriza a una mente ávida de conocimiento, en donde no le basta la teoría desarrollada a la fecha por las Ciencias Económicas y se asume que lo que se le escapa a los modelos canónicos no tiene una mayor relevancia en sí.

En particular, el autor propone no tratar a todos los seres humanos como Econs ${ }^{2}$ sino como lo que somos, Humanos:

Cometemos errores y no valoramos los bienes de una manera necesariamente correcta. Por ejemplo, valoramos más los bienes que son nuestros y no nos percatamos de la invariabilidad de los costos hundidos en las decisiones presentes.
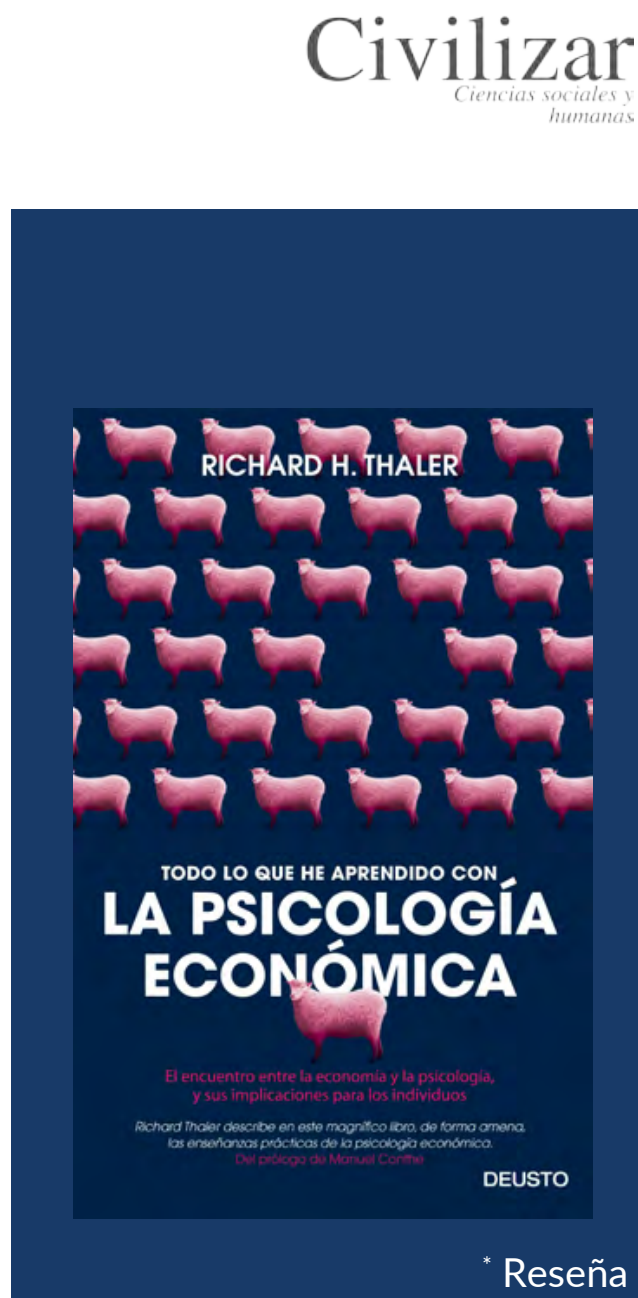

Título original:

Misbehaving: The Making of Be

havioral Economics

Autor: Richard H. Thaler

Traductor: Iván Barbeitos

Año original de publicación: 2015

Edición: Tercera edición (Colombia):

febrero de 2018

Páginas: 528

ISBN: 978-84-234-2554-9

Editorial: Planeta Colombiana S.A.,

Deusto

$\S$ Economista y magíster en escrituras creativas de la Universidad Nacional de

Colombia. Coordinador y docente del Área de Microeconomía de la Universidad

Sergio Arboleda.

Correo electrónico:

sergio.duran@correo.usa.edu.co

(1) ORCID: 0000-0003-4781-1006 Atribución-NoComercialAtribución-NoComercial-
SinDerivar 4.0 Internaciona 
Manejamos el dinero con muchas peculiaridades tanto para consumir, ahorrar o producir. Cuestiona qué tan fungible es el dinero, ya que solemos ponerlo y sacarlo de determinados tarros o asignaciones previamente establecidas por un criterio propio y no muchas veces explicable. En el caso del sector empresarial o público, la existencia de un presupuesto para cada Departamento evidencia esta manera de planificar.

Necesitamos mecanismos, recompensas y castigos que nos ayuden a maximizar nuestro bienestar. Por ello contamos con incentivos ${ }^{3}$ que nos permiten autocontrolarnos, ya que en muchas ocasiones no podemos confiar en nosotros mismos.

Más que ser aversos al riesgo, somos aversos a la pérdida al tomar decisiones en un ambiente de riesgo. No siempre cumplimos con los supuestos y conclusiones de la Teoría de la utilidad esperada ${ }^{4}$, para lo cual se vale de la Teoría de las perspectivas desarrollada por Daniel Kahneman y Amos Tversky 5 .

Valoramos más lo inmediato que lo futuro, lo que muchas veces nos perjudica. Este sesgo al presente por obtener resultados inmediatos ocurre no solo a los consumidores sino a los empresarios; en particular, detalla la forma como los equipos profesionales de Fútbol Americano de la National Football League (NFL) interactúan al adquirir jugadores prometedores y el costo de oportunidad para este tipo de negociaciones.

La falta de consenso en lo que consideramos justo, que se evidencia en los diferentes juegos (varios televisivos) y experimentos que reafirman hipótesis de un comportamiento no necesariamente racional en términos clásicos. Esto se complementa con un análisis detallado sobre lo que entendemos por correcto o equitativo ${ }^{6}$.

Para explicar lo anterior, se vale del recurso de entrelazar dichos factores supuestamente irrelevantes (FSI) con una lista que elaboró para representar esa insatisfacción con las explicaciones a comportamientos que parecían irracionales desde un lente económico clásico.

Unos amigos vienen a cenar, y tomamos unas copas mientras esperamos a que el asado del horno esté listo y podamos sentarnos a la mesa. Para picar, saco un gran recipiente lleno de anacardos, pero después de comernos la mitad vemos que corremos el riesgo de quedarnos sin apetito. Por tanto, me llevo el recipiente y lo escondo en la cocina. Todo el mundo queda satisfecho (Thaler, 2015, p. 50).

En el ítem citado, vemos cómo un evento, al parecer mundano, sirve como punto de partida para un posterior análisis sobre el autocontrol, ya que un Econ no necesitaría que le escondieran los aperitivos, solo no comería más de lo que considera adecuado, porque se asume que es consciente de que su nivel de utilidad futuro se vería perjudicado cuando llegue el asado. Esta naturalidad y sencillez para identificarse con el lector y luego exponer tanto los méritos como las limitaciones de diversos modelos económicos es la que predomina a lo largo de la obra.

Este cuestionamiento en las Ciencias Económicas no es algo novedoso, como cualquier ciencia, evoluciona; parte de este proceso consiste en replantear varios de sus supuestos para dar cuenta de un entorno social cambiante. Tal puede ser el caso de los modelos de crecimiento endógeno, que no les bastó con la explicación exógena dada por Solow; o la forma en la que North y Coase dieron un nuevo enfoque a la economía institucional y los costos de transacción asociados, que a la vez sirvieron a autores como Acemoglu y Robinson (2012) para analizar una nueva institucionalidad desde la lógica de economías y políticas tanto inclusivas como extractivas; o que las corrientes de la economía ecológica vieran al daño medioambiental como algo más que una simple falla de mercado de la corriente neoclásica; o la misma Elinor Ostrom, también merecedora del premio Nobel en 2009, al no estar de acuerdo con la clásica paradoja de los ejidos y demostrar que en la práctica, los bienes comunes sí funcionan cuando se cuenta con acuerdos en la comunidad, y que a su vez podría considerarse como un pilar teórico significativo para el actual desarrollo de la economía colaborativa.

Todos estos grandes pensadores, entre muchos otros que no cito por cuestiones de brevedad, mas no de importancia, suelen caracterizarse por dos cosas: (i) dominan y reconocen el aporte de sus predecesores, y (ii) con sus análisis logran evidenciar algo que para un futuro lector parece ser obvio, pero jamás se le hubiera ocurrido señalarlo: la importancia de la conducta de los individuos en la economía. Así, creo que los aportes que Thaler ha hecho y resume en esta obra son suficientes para considerarlo como 
tal: un gran pensador de la economía del comportamiento. No es casual que coincida con el padre de la Economía, Adam Smith (1776), cuando este último describe a los filósofos como aquellos que aunque parezca que no hacen nada, lo observan todo y así pueden generar ideas innovadoras, al afirmar que "el primer paso para superar las premisas erróneas de la sabiduría convencional es observar al mundo que nos rodea, y verlo tal como es, no como otros pretenden que sea” (Thaler, 2015, p. 486).

No conforme con captar la atención del lector con lo recién descrito, elabora su aporte sobre los empujones o acicates (nudges), donde parte de herramientas psicológicas y sociológicas para implementar y mejorar políticas sociales que promuevan el fin último de la Economía: el bienestar común. Resulta grato, por medio de esta obra, conocer la existencia y labor de instituciones como el Programa de economía del comportamiento de la Russell Sage Foundation en Nueva York, donde cada vez es mayor el número de economistas que quieren complementar su formación con la psicología; laboratorios como Ideas42; los proyectos que llevó a cabo en Estados Unidos el Social and Behavioral Sciences Team (SBST) liderado por Maya Shankar, y los que lidera el Behavioural Insights Team (BIT) en Reino Unido.

Si lo que busca el lector es un aperitivo y una sinopsis de las ideas fundamentales que defiende el autor, se recomienda el artículo Economía del comportamiento: pasado, presente y futuro (Thaler, 2018). Luego de esto, probablemente querrá proceder al plato fuerte que, en palabras de Michael Lewis, logra uno de los efectos más buscados por cualquier escritor: "Michael se llevó una buena parte del libro a uno de sus viajes y tras leerlo me mandó un correo electrónico de solo tres palabras que decía: «iNo es aburrido!»” (Thaler, 2015, pp. 521-522). En última instancia, para finalizar, señalar lo obvio y no hacer esta reseña más larga de lo necesaria, muy recomendada su lectura.

\section{Referencias}

Acemoglu, D., y Robinson, J. A. (2012). Por qué fracasan los países. España: Deusto.

Kahneman, D. (2012). Pensar rápido, pensar despacio. Madrid, España: Editorial Debate.

Levitt, S., y Dubner, S. (2005). Freakonomics (3. ${ }^{a}$ Reimp.). Madrid, España: Zeta Bolsillo.
Levitt, S., y Dubner, S. (2009). Super Freakonomics. La segunda explosiva parte de Freakonomics (1. ${ }^{\mathrm{a}}$ Ed.: mayo de 2010). Bogotá, Colombia: Editorial Debate.

Sandel, M. J. (2012). Lo que el dinero no puede comprar (1. ${ }^{\mathrm{a}}$ Ed.). Bogotá, Colombia: Editorial Debate.

Smith, A. (1776). Investigación sobre la naturaleza y causas de la riqueza de las naciones. México D.F., México: Fondo de Cultura Económica, FCE.

Thaler, R. (2015). Todo lo que he aprendido con la psicología económica (3. ${ }^{\mathrm{a}}$ Ed.). Bogotá, Colombia: Editorial Planeta Colombiana S.A., Deusto.

Thaler, R. (2018). Economía del comportamiento: pasado, presente y futuro. Revista de Economía Institucional, 2o(38), 9-43. doi: 10.18601/01245996. v2on38.02

\section{Notas}

1 Valga aclarar que técnicamente no existe un premio Nobel de Economía sino el Premio del Banco de Suecia en Ciencias Económicas en memoria de Alfred Nobel.

2 Típicos agentes de los modelos económicos tradicionales que poseen una racionalidad perfecta e infalible.

3 Para ahondar sobre el tema de incentivos se recomiendan las obras de Levitt y Dubner (2005; 2009).

4 Cuyos representantes más significativos son Von Neumann y Morgenstern, quienes formalizaron la Teoría de juegos.

5 Se recomienda abordar la obra de Kahneman (2012).

6 De igual forma, se recomienda a Sandel (2012) para ahondar en temas de la justicia, ética y moral inherentes en una economía de mercado actual. 
